\title{
Socialização e poder no campo das pessoas em situação de rua na cidade de São Paulo
}

\author{
Socialization and poweron the field of street people in \\ the city of São Paulo
}

\section{Socialización y poder en el campo de las personas en situación de calle en la ciudad de São Paulo}

\section{Carolina Teixeira Nakagawa Lanfranchi ${ }^{1}$ \\ Viviane Canecchio Ferreirinho ${ }^{2}$}

\begin{abstract}
Resumo: O artigo entende a população em situação de rua como um campo. Assim, busca as especificidades de seu capital, lutas postas pela diferença de poder entre sujeitos, as regras inerentes ao campo e habitus. A essência da teoria de Bourdieu está sempre a serviço para compreender como os esquemas de dominação e poder simbólico estão estruturados na sociedade. A tarefa de aplicar sua teoria à população em situação de rua de São Paulo começa por defini-la como um campo, em seguida analisam-se dados empíricos específicos para a compreensão de parte de seus bens simbólicos particulares. Em conclusão, o estudo indica algumas das variáveis que definem o sistema de disposições inculcadas, que vão desde códigos corporais, densidade do ponto de concentração, acesso a serviços públicos como importantes fatores de distinção e resistência à institucionalização.
\end{abstract}

Palavras-chave: Campo; Habitus; População em situação de rua; São Paulo.

Abstract: The paper understands the homeless population as a field. Thus, it pursues specificities of their capital, struggles due to power differential between them, inherited rules of the field and the agent's habitus. The core of Bourdieu's theory is always at service to understand how the schemes of domination and symbolic power are structured within society. The task of applying his theory to homeless in São Paulo starts by defining it as a field, then analyzing specific empirical data to understand part of their symbolic goods. In conclusion, the study indicates some variables that define the inculcated system of dispositions, with rules ranging from body codes, concentration density point, access to public services', as important factors of distinction and resistance to institutionalization.

Keywords: Field; Habitus; Homeless population; São Paulo.

\footnotetext{
${ }^{1}$ Observatório das Metrópoles (São Paulo, SP, Brasil).

${ }^{2}$ Centro de pesquisa e memória técnica do Observatório de Políticas Sociais (São Paulo, SP, Brasil).

autores.dados_biográficos
}

Civitas, Porto Alegre, v. 19, n. 1, p. 62-81, jan.-abr. 2019

Este artigo está licenciado sob forma de uma licença Creative Commons Atribuição 4.0 Internacional, que permite uso irrestrito, distribuição e reprodução em qualquer meio, desde que a publicação original seja corretamente citada. https://creativecommons.org/licenses/by/4.0/deed.pt_BR 
Resumen: El trabajo entiende la población en situación de calle como un campo. Así, busca las especificidades de su capital, luchas puestas por la diferencia de poder entre sujetos, las reglas inherentes y habitus. La esencia de la teoría de Bourdieu está siempre al servicio de comprender cómo los esquemas de dominación y poder simbólico se estructuran en la sociedad. La tarea de aplicar su teoría a la población en situación de calle de São Paulo empieza por definir la como un campo, luego se analizan datos empíricos específicos para comprender, en parte, sus bienes simbólicos particulares. En conclusión, el estudio indica algunas de las variables que definen el sistema de disposiciones inculcado, que van desde códigos corporales, densidad del punto de concentración, acceso a servicios públicos como importantes factores de distinción y resistencia a la institucionalización.

Palabras-clave: Campo; Habitus; Populación en situación de calle; São Paulo.

\section{Introdução}

Em qualquer centro urbano são perceptíveis grupos que vivem nas ruas. Utilizar os logradouros como moradia não é um fenômeno novo. Contudo, o modelo capitalista flexível é marco definidor para pessoas em situação de rua como conhecemos hoje. $\mathrm{O}$ artigo parte da premissa que essa população é parte das estruturas sociais de classe e de poder, e colocá-la "para fora" da estrutura social reforçaria sua invisibilidade, contribuindo para o aprofundamento da marginalização e a despolitização da condição em que se encontram.

Entender como os sujeitos que utilizam as ruas da cidade de São Paulo para dormir, comer, se relacionar, viver, sobreviver e operar nesse campo será necessário processo reflexivo próprio da sociologia, atentando-se a como certos discursos podem se relacionar com um resgate da exclusão, escamoteando a contradição social fundamental. A população em situação de rua, como parte da camada pauperizada, compartilha a especificidade dada pela ausência de moradia tendo a rua como alternativa e espaço de interação. O conceito de exclusão é insuficiente, pois se refere à condição e não elucida as particularidades em disputa por posições do campo.

O espaço social me engloba como um ponto. Mas esse ponto é um ponto de vista, princípio de uma visão assumida a partir de um ponto situado no espaço social, de uma perspectiva definida em sua forma e em seu conteúdo pela posição objetiva a partir da qual é assumida. O espaço social é a realidade primeira e última [...] (Bourdieu, 2011, p. 27).

As análises desenvolvidas neste artigo servem-se de pesquisas censitárias de 2000, 2009 e 2015 e dados primários de sistemas informatizados 
denominados Sisa (Sistema de Atendimento aos Usuários) e SISRua (Sistema de Informação da Situação de Rua). Assim, busca delimitar a população em situação de rua como espaço social dotado de regras e posições sociais, que inculca uma estrutura de disposições práticas, habitus, promovendo a distinção de seus agentes dos demais membros da sociedade e que, também, os diferencia entre si: "como um campo de forças, cuja necessidade se impõe aos agentes que nele se encontram envolvidos, e como um campo de lutas, no interior do qual os agentes se enfrentam, com meios e fins diferenciados conforme sua posição [...]" (Bourdieu, 2011, p. 50).

Construir o espaço social significa superar a visão individualista, portanto, entendê-lo como parte da estrutura de poder, "essa realidade invisível, que não podemos mostrar nem tocar e que organiza as práticas e as representações dos agentes" (Bourdieu, 2011, p. 24). O campo é construído na sua relação com o exterior, condições de classe dada pela relação desse conjunto com a estrutura social. Mas também, pela sua relação com o interior, parte importante para compreender habitus e tomada de posições. Onde o capital é disputado configura-se a hierarquia.

\section{Na estrutura social a condição de rua}

No Brasil, a designação "mendigos", foi sucedida por "vagabundos", "moradores de rua", até chegar à atual definição "em situação de rua" quando são reconhecidas as heterogeneidades, os sofrimentos distintos e os determinantes socioeconômicos da degradação (Neves, 2010a). Assim, as mudanças de termos correspondem às formas de representação revelando-se uma mudança de paradigma, especialmente em 1990, quando a administração pública começa a se preocupar com a utilização dos espaços públicos. A população no Brasil conquistou uma série de direitos, na forma de leis, decretos e movimentos. Sendo o principal, a recente Política Nacional para População em Situação de Rua, resultado de mobilizações e pesquisas. ${ }^{2}$

Um aspecto importante para o estudo diz respeito ao acesso aos serviços, refletindo na capacidade de representação e participação política.

\footnotetext{
${ }^{1}$ Ligado a uma visão criminalista pela centralidade do trabalho como dignidade humana. Código Criminal do Império (1830), capítulo IV: “Art. 295. Não tomar qualquer pessoa uma occupação honesta e útil de que possa subsistir, depois de advertida pelo juiz de paz, não tendo renda sufficiente" (Brasil, 1830). É somente em 1940 que vemos a vadiagem e a mendicância com status alterado de crime para contravenção.

${ }^{2}$ Em 2005 é realizado I Encontro Nacional sobre População de Rua em Situação de Rua, em 2006 publica-se o decreto que constitui um Grupo de Trabalho Interministerial com a finalidade de elaborar estudos e apresentar propostas de políticas públicas. Em 2007-2008 foi realizada a Pesquisa Nacional da População em Situação de Rua, gerando decreto específico (Brasil, 2009).
} 
Por isso, é interessante a análise de Webb (2017) que identifica, na década de 1980, políticas caracterizadas pela emergência, já nos anos 1990 o foco residia na criminalização de alguns comportamentos "desviantes" e nos anos 2000 na noção de "eficiência" das ofertas. A autora ainda argumenta que as mudanças nas abordagens relacionam-se com a relativa ausência de poder da população "desviante" da estrutura social e como esta se insere na democracia representativa:

homeless population has rarely organized successfully enough to reach the agendas of legislators. In the few examples where they have achieved significant organization, the policies that result from this activism tend to align much more with policymakers' goals than the desires of homeless advocates (Webb, 2017, p. 13-15).

O interessante é que a autora aponta os efeitos da representação para a formulação de políticas públicas. No Brasil, seus representantes estão em constante disputa por lugar de defesa, servindo mais para legitimar o local de fala sem com isso superar os modelos de atenção existentes. Os pesquisadores concordam que essa população faz da rua um espaço de ordenação de identidades e espaço de relações privadas. Por isso, torna-se importante incluir a noção de território, permitindo avançar na apropriação do espaço público como "casa", onde o espaço é dividido e disputado, sendo estabelecidas fronteiras. Stoffels (1977) traz com clareza as relações com o espaço público:

tenta estabelecer território próprio num espaço determinado para uso comum [...], de várias maneiras: 1) um só lugar, funcionando como único local de trabalho ou habitat total; 2) vários lugares, funcionando como locais de trabalho múltiplos ou habitat dividido; 3) o território apropriado - em caráter de habitat total ou dividido, ou como configuração única ou parcelada de locais de trabalho inserido no meio ambiente global (de uso público): utilização do espaço urbano como lugar de festa e área de comunicação com outros indivíduos [...] (Stoffels, 1977, p. 144).

Soma-se a sistematização que relaciona o período de referência à noção de territorialidade. Vieira et al. (1994) conceituam que a população pode ser diferenciada entre aqueles que "são da rua", que "estão na rua" e aqueles que "ficam na rua". As pesquisas servem para verificar a multidimensionalidade do fenômeno e indicam a adequação do conceito de campo para compreender as condições dessa população. De uma maneira geral, os estudos revelam que é o baixo nível de renda que impede o acesso à habitação, dificulta o emprego, 
o estabelecimento de redes de proteção, entre outros aspectos. O perfil médio, descrito a seguir, é revelador da condição de rua.

No levantamento de 2000 existiam 8.706 pessoas em situação de rua na cidade de São Paulo, sendo 5.013 nas ruas. Em 2015 foram identificadas 15.905 pessoas, sendo 7.335 nas ruas. Os dados censitários (Smads/Fipe, 2000, 2009; Cops/Smads/Fipe, 2015) revelam que trata-se de uma população majoritariamente composta por homens, ${ }^{3}$ sozinhos, adultos, não brancos, ${ }^{4}$ com baixo nível de escolaridade, que chegaram às ruas por rompimento de vínculos familiares ou desemprego, com incidência de questões de saúde mental superior à média observada para a população em geral.

Estes levantamentos colocam como premissa que a condição de excluído é anterior à própria alternativa da rua como moradia. Assim, a condição de rua é marcada por essa exclusão extrema, pela impossibilidade de reprodução nos moldes hegemônicos. Portanto, são sujeitos impossibilitados de manter as suas condições de reprodução que encontram nos logradouros e serviços de acolhimento as alternativas de sobrevivência.

\section{No campo as posições, disposições e trajetórias}

\section{Dinâmicas do campo}

Outro sinalizador da complexidade de relações nesse campo reside no reconhecimento de distinções dentro dessa população aparentemente homogênea. É nas diferenças que se vislumbra as posições dos agentes no campo. No Brasil é dada pela clara separação entre os que estão acolhidos e os que dormem em locais abertos e públicos. Para compreender essa distinção de forma empírica, foi construída uma análise fatorial do conjunto geral das variáveis do Censo (Cops/Smads/Fipe, 2015), verificando as características que os aproximam e que os distinguem.

Ainda que inicial, os resultados apontam que as variáveis raça/cor, nível de escolaridade e tempo de rua são significantes por diferenciá-los em relação aos demais campos sociais, serve para compreendê-los na sua condição de rua. Adicionalmente, tem-se o agrupamento de variáveis distintivas da sua posição no campo: 1) entre os acolhidos: vive só; trabalha em emprego

\footnotetext{
${ }^{3}$ Em 2000, o sexo masculino representava 84,8\% do total, em 2009 passou para 82,9\% e em 2015 era $86 \%$. Esses dados demonstram que prevalece a característica global de maioria masculina (Smads/Fipe, 2000, 2009; Cops/Smads/Fipe, 2015).

${ }^{4}$ Quanto à caracterização do atributo raça/cor, em 2000 os brancos eram 38,3\%, em 2009 baixou para $30,7 \%$, em $2011,25 \%$ e em 2015 subiu para $30 \%$. Ou seja, uma população predominantemente composta por "não-brancos" (Smads/Fipe, 2000, 2009; Cops/Smads/Fipe, 2015).
} 
formal ou informal; exerce atividade com contratante, recebe benefícios de transferência de renda (condicionado ou continuado, não contributivo), faixa etária superior; 2) entre os que pernoitam nas ruas: tempo na cidade, exercem alguma atividade para conseguir dinheiro, pedindo ou em atividade ilícita, egressos do sistema carcerário, consumo de álcool e outras drogas e maior incidência de violência. Embora essa identificação seja mais nítida entre dois grupos, outras aquisições próprias ao campo distinguem posições diferentes entre os agentes. A observação estatística indica as disposições daqueles que são mais independentes e com maior grau de rompimento com aspectos da ordem legitimada, até os que se encontram totalmente institucionalizados e reconciliados com esses mesmos aspectos.

Para Paugam (2003, p.65) o processo de desqualificação engloba indivíduos que, pela deterioração progressiva de laços de solidariedade, experimentam processos alternados de fragilização, assistência, marginalização e inserção social. Ele estabelece três tipos de beneficiários: 1) os fragilizados, que se beneficiam de intervenções pontuais dada às incertezas ou irregularidades de renda; 2) os assistidos, que se beneficiam de intervenção regular e intensa, tendo aprendido a se identificar com esses papéis, status e discursos institucionalizados e comportamentos que correspondam às expectativas; e 3) os marginalizados, são "muito menos enquadrados pelos profissionais da ação social, [...] devem se organizar para reconstruir um espaço cultural tolerável ou tentar rejeitar essa situação objetiva humilhante" (Paugam, 2003, p. 65-66).

Esta "cerimônia de degradação do status", processo de aceitação ou resistência aos rótulos, discursos e regras, é fator importante para a compreensão das relações de poder entre os sujeitos do campo. Observa-se que existem aqueles mais aptos à incorporação de discursos institucionalizados e que, portanto, mantêm relação de vínculo com as instituições e com os profissionais e, por outro lado, aqueles menos aptos à aceitação ou submissão a essa "cerimônia" e que mantêm relações pontuais com os sujeitos institucionais.

Com a realização da distribuição estatística ${ }^{5}$ (Cops/Smads/Sisa, 2015) dos acolhidos por tipo de vínculo reforçam-se indícios de uma relação diferente com a rede. Existem aqueles que possuem relação continuada, os quais se denominam vinculados ou vaga fixa. Esses revelam uma incorporação dos discursos e práticas (habitus) necessárias ao processo de negociação e compõem

\footnotetext{
${ }^{5}$ Distribuição normal e percentual dos Tipos de Acolhidos (pernoite e vinculado), por faixa etária (0-11 anos, 12-17 anos, 18-30 anos, 31-49 anos, 50-59 anos, 60 ou mais) e Sexo (feminino e masculino), com dados oriundos do Sisa (Sistema de Atendimento aos Usuários), da cidade de São Paulo (Cops/Smads, 2015).
} 
uma maioria de adultos acima de 31 anos do sexo masculino e menores de 17 anos idade do sexo feminino. ${ }^{6}$ Tem-se um grupo dentro dos acolhimentos que utiliza o serviço como moradia provisória/permanente. Provisória, porque há obrigatoriamente regras a cumprir e, permanente, quando vai permanecendo diante da falta de soluções habitacionais integradas e estáveis. Já aqueles resistentes à institucionalização ou às condições de vida nas ruas, e que acabam por estabelecer uma relação pontual, servindo de alternativa às circunstâncias (temperatura, chuva, brigas, deslocamentos, alimentação, higiene pessoal etc.), denominam-se pernoite. O universo de acolhidos transitando entre serviços é majoritariamente composto por jovens adultos do sexo masculino. ${ }^{7}$

Na pesquisa de De Peretti (2005) observa-se também duas classes de pessoas a partir do aspecto temporal da relação estabelecida com os serviços e com a própria situação de rua, com trajetórias nem sempre lineares e contínuas. O autor, ao tratar o precariado como frágil na sua posição social e instável na sua condição social, traz a diferenciação entre os que estão chegando (entrants) e os que estão saindo do campo (sortants). Para entrar no campo, há primeiramente a condição de exclusão, como já visto. Observa-se, portanto, a ocorrência de perdas sucessivas de capitais legitimados socialmente: trabalho, família, recursos financeiros, moradia, saúde, documentos de identificação social etc. Além disso, alguns são egressos de instituições como hospitais psiquiátricos ou do sistema prisional, havendo, portanto, um processo de desinstitucionalização não cuidada. Uma combinação desses fatores, não obrigatoriamente ou compulsoriamente, leva à entrada no campo da rua em que novos capitais terão valor e novas regras serão estabelecidas.

Nessa combinação de fatores, chama atenção o uso de álcool e outras drogas. Na pesquisa amostral (Cops/Smads/Fipe, 2015) identificou-se que faziam uso de álcool e/ou outras substâncias psicoativas antes de irem para as ruas $75,2 \%$ das pessoas acolhidas e $82,7 \%$ pernoitando em logradouros. Portanto, o sofrimento social reflete na saúde mental, aonde o convívio com a rua faz com que percam ou abandonem um estilo de vida, desembocando nela como alternativa de sociabilidade e, por fim, como moradia.

Outro aspecto refere-se às relações de convívio: poucos parecem recuperar ou reinventar os laços de convivência que possuíam antes de ingressarem nas ruas, entre os acolhidos esse o percentual é ainda maior. 80,4\%

\footnotetext{
${ }^{6}$ Em relação ao total geral de acolhidos, $87 \%$ estão vinculados, sendo $85,6 \%$ do sexo masculino, $61,3 \%$ entre 31 e 59 anos. Entre o sexo feminino vinculados chama atenção o dado de que $21,7 \%$ têm até 17 anos.

${ }^{7}$ Considerando o universo de acolhidos em pernoite, $94 \%$ são do sexo masculino e $75 \%$ têm entre 18 e 49 anos.
} 
dos acolhidos e 69,3\% dos que pernoitam nas ruas vivem sós. Antes de irem para rua, essa proporção era de $26 \%$ e $18 \%$ respectivamente (Cops/Smads/ Fipe, 2015). Essa informação aproxima os dois extremos do campo. Vivem sós, tanto os mais independentes das regras e menos submissos às normas sociais legitimadas, como também aqueles que mais cumprem as regras, os mais institucionalizados, mais próximos da saída do campo. A vida na rua é uma verdadeira fábrica de solidão.

Assim, elaboramos o quadro (figura 1) que ilustra os quatro grandes grupos que conformam as posições no campo, na perspectiva defendida neste artigo. Seria um campo de entrada e saída, não fosse um problema de ordem estrutural e cíclico que provoca recaída ou permanência. Portanto, essas grandes categorias representam aquisição de disposições próprias de cada grupo. Isso implica, mais adiante, em discutir os habitus adquiridos na socialização no universo da rua e no rompimento com disposições feitas pela (re)socialização nas instituições.

Figura 1 - Síntese de posições do campo da população em situação de rua da cidade de São Paulo

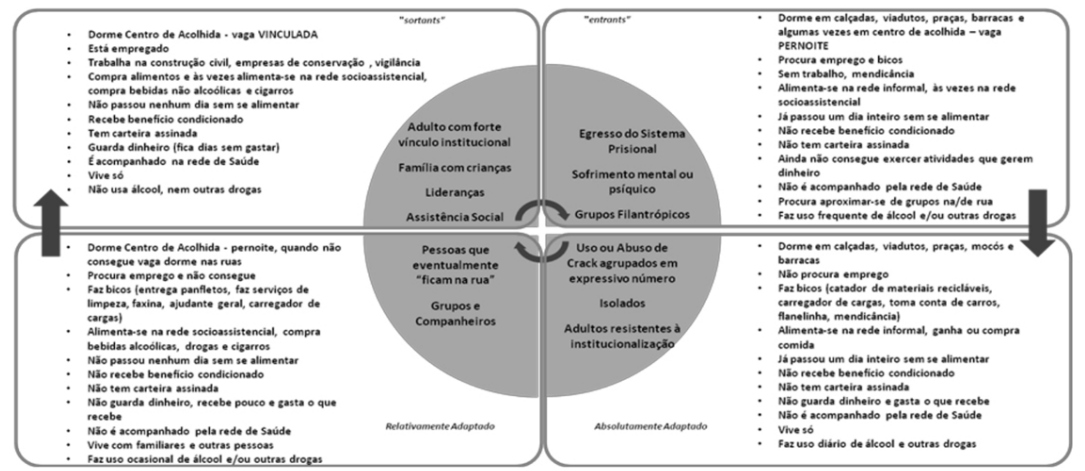

Fonte: Elaboração das autoras.

A vida nas ruas representa uma série de situações extremas de ruptura de relações familiares e afetivas. Dentro do campo são percebidas posições distintas, entre aqueles que pernoitam estão os que estão entrando não adaptados e os que estão há mais tempo, relativamente adaptados. Os resistentes às regras institucionais são os absolutamente adaptados e os que estão saindo com forte vínculo institucional que denominados acolhidos vinculados. 


\section{Sistema de disposições}

A população em situação de rua produz práticas que os diferenciam entre si e dos demais grupos da sociedade, a exemplo do que diz Wacquant (2003) sobre os guetos negros nas grandes cidades dos Estados Unidos: "não sofre de desorganização social, mas se constituem em um universo dependente, finamente diferenciado e hierarquizado que se organiza segundos princípios específicos produtores de uma forma regular de entropia social" (Wacquant, 2003, p. 184). O mesmo é percebido para a população em situação de rua, pois, ao habitarem o espaço público, reivindicam outro uso frente ao legitimado. Fazem parte da lógica de exclusão que é senão uma dominação total e mais feroz, sem com isso suplantar elementos finos de diferenciação. Essa compreensão é reforçada por Neves (2010b) quando identifica que perdem capital legitimado socialmente até chegarem a essa situação, ao mesmo tempo em que são alvo de rótulos e atributos socialmente reconhecidos. Evidencia, portanto, que existe capital simbólico na situação de rua.

Segundo Bourdieu (2011) entrar e manter-se no campo requer grandes investimentos por parte dos agentes (tempo, capital etc.). Compreende que quando o campo é frágil, pouco autônomo, ele demanda estruturas externas agindo pela coerção ou coação. No caso da população em questão, a fragilidade e a autonomia do campo são dadas pela condição de exclusão, assim pode-se afirmar que existem estruturas agindo pela coerção ou coação. Complementarmente, entendendo que as instituições são mediações que influenciam a dinâmica de acumulação e de luta (Harvey, 2012, p. 54), tem-se a centralidade reforçada da relação com os serviços de acolhimento, com as instituições assistenciais etc.

A trajetória de vida na rua tem início com um conjunto de perdas de bens e valores objetivos e simbólicos. Uma vez vivendo na rua ficam sujeitos às regras estabelecidas que inicialmente desconheçam. A própria população tem termos específicos para essa entrada: é o baque ou engolir a rasteira (Rosa, 2005, p. 275). Nessa interação cotidiana vai-se aprendendo, apreendendo e incorporando um novo estilo de comportamento e de relações.

As gírias e expressões usadas criam a cumplicidade e reconhecimento dos iguais, além de intimidarem os que não pertencem ao campo: "Assim como as posições das quais são produtos, os 'habitus' são diferenciados; mas são, também, diferenciadores" (Bourdieu, 2011, p. 22).

A linguagem própria é uma forma bastante assertiva de desconstrução da sua invisibilidade. Assim, os agentes em interação com esses grupos têm também que aprender a se comunicar utilizando suas expressões linguísticas e 
a linguagem corporal específicas dos moradores de rua. Nas palavras de Vieira et al. (1994): "Quanto maior o tempo na rua, maior a dificuldade de restabelecer os laços anteriores [...]. Sua aparência vai mudando: as roupas, o andar lento, fazem com que seja identificado socialmente como um homem de rua" (Vieira et al., 1994, p.99). As roupas vão se desgastando, o cabelo crescendo, o cheiro de vários dias sem banho se faz sentir etc. Eles, os habitantes das ruas, precisam saber onde comer, onde fazer necessidades fisiológicas, onde encontrar água para beber, preparar alimentos, lavar roupas, onde conseguir uma muda de roupa, saber defender-se, lidar com a polícia, dormir perto de alguém para se proteger da violência de agentes externos e internos ao campo. A permanência no campo envolve situações diferentes ao longo do tempo. A classificação que as autoras (Vieira et al., 1994) elaboram determina posições distintas no campo: 1) os que ficam na rua, que tangenciam o campo, às vezes ingressando nele, outras superando a condição inicial retornando à estrutura de vida anterior ou próxima dela; 2) o estar na rua, aqueles que estão ingressando e aprendendo as regras com os mais antigos; e, por fim, 3) aqueles que são de rua e já ocupam lugar no campo, conhecem suas regras e sobrevivem nelas e delas.

Após a socialização inicial e o entendimento das principais regras, há o reconhecimento das possibilidades de aquisição daquilo que é valioso entre os sujeitos que se relacionam nesse campo. Vieira et al. (1994) afirmam que, ao mesmo tempo em que a pessoa na rua tem perdas, tem, também, aquisições. Perdem o convívio familiar, mas instituem novas formas de vínculos com companheiros, grupos etc. Os moradores de rua perdem a condição de consumidores de bens e serviços, mas ganham alguns desses bens e serviços de instituições ou grupos informais. Ainda, perdem responsabilidades, obrigações e compromissos de toda ordem (familiar, institucional etc.) e estabelecem relações de solidariedade e companheirismo. Pode-se dizer que há ganhos, portanto, há capital, sendo assim, há troca, há disputa, há poder. Quanto mais tempo na rua, mais se conhece e se adquire os capitais da rua, conforme fala de um informante morador de rua: aqui consigo viver sem ter que responder pra ninguém, nem meus familiares, nem a sociedade.

Em termos de fontes de aquisição de alimentos os dados censitários (Cops/Smads/Fipe, 2016) permitem identificar que entre os acolhidos a procura é menos diversificada do que no grupo pernoitando nas ruas. Para esses últimos, a coleta e a catação é quatro vezes maior (20,4\% pernoitam nas ruas e 5\% acolhidos), receber e ganhar de grupos de distribuição é mais que o dobro (28,9\% entre acolhidos e $60,6 \%$ nas ruas). Os números relevam o grau de insegurança alimentar que ambos vivem, sendo mais grave entre aqueles nas 
ruas. É evidente que a não institucionalização fragiliza o acesso à alimentação, o que explica a informação de que $35 \%$ dos que dormem nas ruas passaram um dia inteiro sem comer contra $18 \%$ dos acolhidos. Contudo, temos que salientar que a rede de acolhimento não vem garantindo a alimentação em períodos diurnos, refletindo na manutenção das formas de alimentação apreendidas na situação de rua. Por isso mesmo, pode-se deduzir que o conhecimento da rede é importante à sobrevivência. Conhecer e dominar essas fontes são capitais importantes.

A situação de rua amplia a pressão para exercer alguma atividade e a partir do tipo de vínculo com o trabalho ou a ausência dele (Cops/Smads/ Fipe, 2015) percebe-se que o acolhimento amplia o acesso ao emprego regular (17,9\% trabalham empregados, $57,7 \%$ com bicos e $25,8 \%$ não trabalham). Porém, entre os acolhidos aumentam as possibilidades de empregos dentro de relações empregador-empregado: de $10 \%$ a $20 \%$ realizam atividades de distribuir panfletos, serviços de limpeza/faxina e ajudante geral. Já entre os que pernoitam nas ruas vemos grande concentração nas atividades por conta-própria para atender necessidades mais imediatas (4,8\% trabalham empregados, $73,8 \%$ com bicos e 20,7\% não trabalham). O bico é a principal estratégia de obtenção monetária nas ruas: como catação de materiais recicláveis e mendicância ou ainda carga/descarga e flanelinha. As atividades ilícitas como roubo/assalto e venda de drogas é significativa entre os que estão nas ruas, assim como a prostituição, sendo quase três vezes maior do que entre os acolhidos.

A luta e conquista de espaços na cidade que permitam o acesso aos recursos é significativa para avançar no entendimento de seus capitais. Por isso, cabe analisar os dados disponíveis que permitam perceber configurações de ocupação do território. Em 2015 foram encontrados 2.802 pontos com pessoas pernoitando nas ruas, sendo que em $60 \%$ desses foi encontrada apenas uma pessoa, em $36 \%$ foram encontradas de duas a nove pessoas e em 3,5\% mais de dez indivíduos. Ou seja, a maioria nas ruas vive só e 4 em cada 10 vivem em grupos de até 9 pessoas como estratégia de proteção à vida e às forças de expulsão.

Outro dado relevante refere-se à característica do entorno, sendo $57 \%$ em áreas próximas à concentração de comércio e serviços e $28 \%$ em locais de uso misto (residências e comércio conjugados). Apenas $12 \%$ estão em pontos predominantemente residenciais. $\mathrm{O}$ uso de barracas como solução de proteção e estratégia de permanência vem aumentando. Em 2015 identificouse 331 pontos com barracas, representando $12 \%$ do total de pontos, sendo $47 \%$ em pontos com mais de 10 pessoas. Quanto mais próximo ao centro urbano tradicional ou centralidades polares, maior a concentração de barracas 
e também de pontos de permanência de indivíduos sós. Conforme Neves (2010b):

Para sobreviverem na rua, $[\ldots]$ se organizam em pequenos grupos, invisíveis se a repressão social é intensificada e visíveis se esta é relaxada. A participação nesses grupos visa ampliar e controlar os recursos e obter maior segurança perante as diversas ameaças e agressões a que estão sujeitos. Como não podem acumular recursos visíveis, $[. .$.$] se valem do horário e dos locais em que há maior$ fluxo de pessoas [...], tentarão de escolher um local para fixação usando como critérios a proximidade de fontes de água [...] e abrigos que lhes permitam minimizar os efeitos das condições naturais e os tornem relativamente despercebidos durante a noite (canto de dormir ou se encostar) [...]. As tentativas de reconstrução da casa em locais públicos são altamente controladas e recriminadas, pois representam uma inversão dos princípios sociais (grifo nosso) de classificação dos espaços públicos e privados, uma confusão entre os domínios da "rua e da casa" [...] (Neves, 2010b, p. 11-112).

A partir dessa ressignificação do espaço público na situação de rua que se faz o capital representado pela localização; os recursos urbanos de seu entorno coloca-o como estratégico à sobrevivência. Ao inverter os princípios sociais de classificação dos espaços públicos provoca o incomodo da ordem hegemônica, demandando intervenções das políticas públicas.

Uma análise mais detalhada das taxas geométricas de crescimento por distrito revela que o deslocamento desses pontos seguiu a transformação da cidade industrial para a cidade dos serviços. No processo de reconversão os atributos urbanos (marquises, viadutos, concentração de serviços etc.) são fatores primeiro de atração desta população em oposição às pressões especulativas de renovação urbana ou mesmo de disponibilidade de serviços de acolhida.

Esses dados são comprobatórios da importância do estabelecimento da rede de relações, do conhecimento das ruas e das possibilidades de solucionar rapidamente situações de risco na rua. Sabe-se que aqueles que melhor conhecerem os meios de sobrevivência na rua, para conseguir alimentação, recursos financeiros e proteção, mais poder e maior resistência à institucionalização apresentarão. As apropriações do conhecimento e de formas de ocupação dos diferentes locais geram poder. Portanto, esse é o grande ganho e a grande moeda que circula nas ruas como um capital simbólico.

Em contrapartida, ao cruzar a linha da rua para o acolhimento, as regras impostas são as regras da instituição, e aquele poder exercido nas ruas, se altera, reconfigurando as disposições estabelecidas e a própria percepção 
pelos agentes. A começar pelas disputas: da vaga de pernoite, ficar na porta do serviço ou esperar um encaminhamento; horários de entrada e saída, para acordar, comer etc. Tudo para depois voltar para a rua. A principal restrição à entrada e/ou permanência de usuários imposta pelos serviços é do uso de álcool e outras drogas. Essa regra acaba contribuindo para a dobradinha rua/acolhida em que aparecem aqueles que não estão totalmente institucionalizados e os resistentes à institucionalização que pernoitam nas ruas.

\section{Movimentos de luta}

Conforme discutido, não se pode falar de campo sem falar das relações de poder e disputas entre os sujeitos. Para isso é fundamental abrir mão dos valores inculcados fora do campo. As falas de pessoas na condição de exclusão social elucidam um ponto de partida, segundo Amber Ruffin (2006) em entrevista a Seth Meyers:

O pensamento de que alguém acredite que você mereça menos direitos por causa de quem você é, é deprimente. Mas aí você realiza que fazendo o que você faz todo dia, você prova para eles que você é incontivel. Eles podem gastar o tempo deles tentando aprovar leis que tirem seus direitos e silenciar a sua voz, mas tudo o que você tem que fazer é viver a sua vida bem na cara deles, provando que nós somos incessáveis [Tradução livre].

Essa resistência que se dá pela simples existência parece ser elemento importante para compreender a posição do sujeito isolado na condição de rua, comumente denominado crônico. Quando um agente social, apoiado pelo estado, procura afastar, seja pela força ou pelo convencimento, o sujeito da rua pela via da institucionalização, ele está expropriando seu modo de reprodução baseado no trabalho independente ou livre, também o conhecimento do campo e o habitus que reforçam a tomada de posição e criam a hierarquia de poder. Essa resistência é o que lhe resta querer, enquanto sujeito que ainda quer algo, estando e vivendo à margem do sistema. Não significa afirmar que seja bom estar em situação de rua, mas que o que é poder neste campo tem que ser compreendido pela análise do seu capital simbólico próprio. Se a resposta fosse conceder moradia, estaríamos enfrentando o verdadeiro problema: a rua enquanto alternativa de vida.

A própria política de assistência social contribui com a determinação de uma trajetória no campo, ao prever um modelo de gradativa institucionalização até a saída para a autonomia. Estudos portugueses (Duarte, 2018) e brasileiros (Kohara, 2018) desqualificam esse modelo, pois revelam que essa população 
quando consegue a moradia organiza rapidamente outros aspectos de suas vidas, evidenciando como preconceituosa a ideia de que é preciso dar-lhes as condições ou aprendizado para poderem viver autonomamente em moradias.

As políticas públicas visam promover a recapitalização econômica, ou como diz Neves (2010b), devem proporcionar que voltem a serem capazes de se reproduzirem como força de trabalho. Ou seja, devem permitir que os sujeitos em situação de rua possam participar de outro campo, ocupando uma nova posição, que se define pelas regras e atores desse novo espaço, sem com isso destituí-los dos capitais adquiridos nas ruas, como reza o ditado popular "tira-se o sujeito da rua, mas não se tira a rua dele". Assim, conforme Bourdieu (2011):

O habitus preenche uma função que, em outra filosofia, confiamos à consciência transcendental: é um corpo socializado, um corpo estruturado, um corpo que incorporou as estruturas imanentes de um mundo ou de um setor particular desse mundo, de um campo, e que estrutura tanto a percepção desse mundo como a ação nesse mundo [...]. Os agentes que lutam por objetivos definidos podem estar possuídos por esses objetivos. Podem estar prontos a morrer por esses objetivos, independentemente de qualquer consideração em relação aos lucros específicos, lucrativos, da carreira ou outros. Sua relação com o objetivo que lhes interesse não é de modo nenhum o cálculo consciente de utilidade que lhe confere o utilitarismo [...]. Eles têm o sentido do jogo; [...] eles podem realizar, de maneira espontaneamente desinteressada, ações que estejam de acordo com seus interesses (Bourdieu, 2011, p. 145-147).

Por isso que o capital da situação de rua manifesta-se como grau de conhecimento das fontes de recursos, das territorialidades etc., que faz com que o mais apto resista à coerção ou coação das instituições que operam no campo. O sujeito mais distante dos padrões sociais hegemônicos e mais adaptado à vida e à sobrevivência nessas condições possui maior poder. Os mais próximos à saída do campo, seja pela adesão ao discurso da ordem social, por superação da situação que os trouxe ao campo, ou ainda, pela condição de lideranças na luta por políticas públicas adequadas, têm menos poder no campo da rua e maior poder no campo econômico ou político.

A figura 2 busca ilustrar a hierarquia, do menor para o maior poder: 1) Lideranças (acolhidos com alto grau de institucionalização ou ex-moradores de rua); 2) Acolhidos em vaga fixa em relação de longo prazo com a rede de serviço; 3 ) grupos ou indivíduos que alternam entre pernoite e acolhimento nos serviços, que apresentam relativo grau de institucionalização, que tendem a 
viver em grupos nos diferentes pontos de concentração; 4) indivíduos isolados, comumente considerados crônicos, com forte resistência à institucionalização.

Figura 2 - Hipótese da hierarquia: síntese da relação de poder no campo

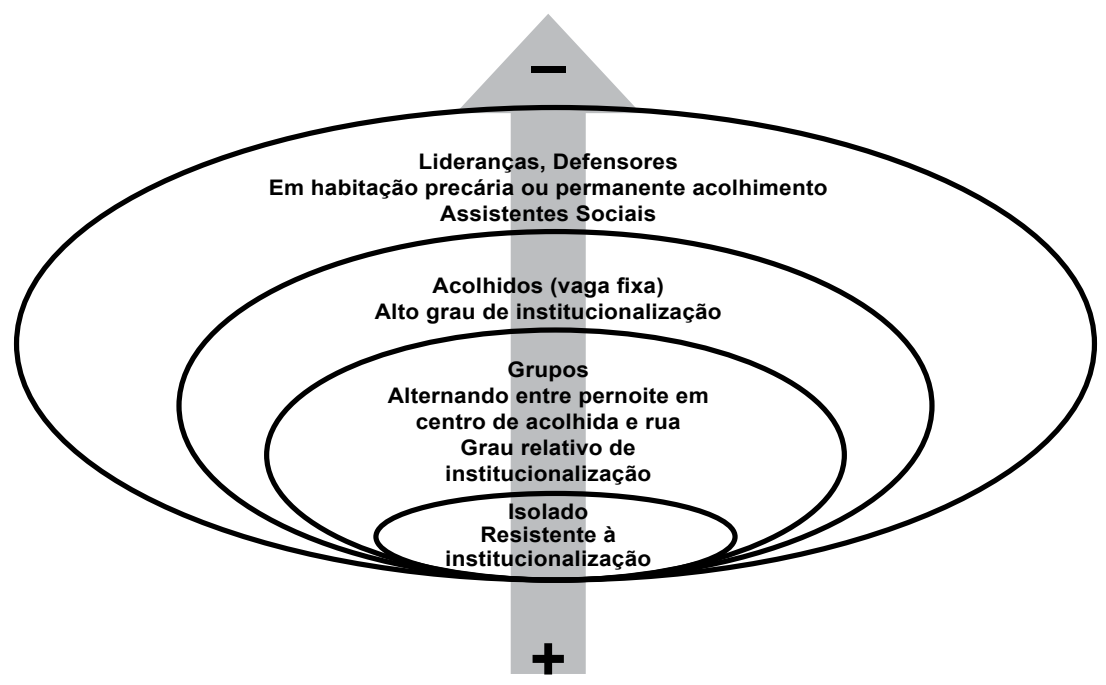

Fonte: Elaboração das autoras.

Com o avanço no entendimento dessa população como portadora de direitos civis, vemos surgir dentre os agentes do campo personalidades que buscam representar os anseios desse campo na arena da elaboração de legislações e políticas públicas específicas. Trata-se de uma forma de liderança que nasce do conflito e se faz nele, seja pela posição no campo, seja pelo papel atribuído a ele. A defesa se faz a partir de discursos e práticas institucionalizadas, seja pela via diagnóstica, administrativa ou ainda pela narrativa de vida. Dentre esses, considerarmos algumas formas: 1) aqueles reconhecidos pelo estado como lideranças, que participam oficialmente de espaços de disputa e dialogo na administração pública e que também são reconhecidos pela população em situação de rua; 2) aqueles reconhecidos pelo estado e não pela população; 3) aqueles reconhecidos pelo segmento que buscam defender e representar, mas não o são pelo estado.

A legitimação desses se faz ao menos por duas vias: aqueles que vivenciaram a situação de rua e aqueles estudiosos ou trabalhadores sociais que são simpáticos à condição motivados pela contradição própria de sua 
atividade. Neste último caso, como coloca Bourdieu (1998, p. 2), trata-se da mão esquerda do estado que, precarizada, sente-se frustrada por não mais ser guardiã do interesse público e responsabilidades coletivas, e encontram na representação política parte da satisfação frente à impotência de alterar essa condição de vida.

A legitimidade, como um capital simbólico, é conquistada pela capacidade de mobilização e pela imposição de uma visão que depende da autoridade social adquirida nas lutas anteriores, advindo da experiência particular de rua negando vivências fora do campo (vocês não sabem o que é passar fome ou frio) ou pelo conhecimento dos habitus adquiridos no campo (eu sei o que é o cidadão não ter como dormir com medo da violência policial). Servindo, muitas vezes, de mediadores entre os agentes de fora e os sujeitos do campo essas lideranças são porta-vozes:

existe, se existirem pessoas que possam dizer que elas são a classe, pelo simples fato de falarem publicamente, oficialmente, no lugar dela, e de serem reconhecidas como legitimadas para fazê-lo por pessoas que, desse modo, se reconhecem como membros da classe [...] (Bourdieu, 1990, p. 168).

Outro aspecto é o grau de institucionalização, tanto para definir a legitimidade como para manter-se no poder. O poder de impor uma visão é poder político por excelência. Há os que, há mais tempo no papel de liderança, acabam se distanciando do campo, na medida em que adquirem capital de outro campo e, outros que, presos às percepções da rua, não conhecem ou não adquiriram os habitus das representações políticas e burocráticas, mas que por conhecerem os recursos do campo, encontram certo grau de legitimidade.

A análise de dados de abordagem entre 2009-2017 (Cops/Smads, 2018) revela que a proporção de recusa à oferta de vaga de pernoite manteve-se relativamente próxima desde 2010, a despeito da ampliação e diversificação de vagas. Quando verificamos os motivos de recusa, observamos que variou de 3\% a $1 \%$ aqueles que não aceitam as regras dos serviços e em $2 \%$ a $1 \%$ aqueles que não querem sair de onde estão. Entre 2009-2017, as abordagens que resultaram em encaminhamento efetivo variaram de $41 \%$, para $61 \%$, respectivamente. Por isso, a relevância dos resultados da abordagem, pois reforçam a elaboração da hipótese estruturada neste artigo, de que existe resistência ao acolhimento de um grupo de pessoas e essa capacidade configura-se como capital, na medida em que é central conhecer os recursos de sobrevivência nas ruas para fazer frente à pressão pela institucionalização, o que equivale à sua posição na hierarquia. Dentro desses parâmetros, a resistência à institucionalização se 
apresenta também como o extremo da aceitação e inculcamento da condição e da posição de rua.

$\mathrm{Na}$ competição, entre os diversos agentes do campo, muitas vezes violenta, ${ }^{8}$ a atuação dos agentes públicos está voltada para o paliativo ou para a inculcamento das disposições da ordem social legítima, ou ainda, de valores hegemônicos que reforçam o status desqualificado de sua condição social. É por isso que se tem a impressão de que aquele que está saindo da condição de rua é o que mais tem poder dentro deste campo, quando na verdade, a lógica operada é inversa. Assim como no uso do espaço público como casa; aquele que tem mais disposições práticas para sobreviver na rua tem mais poder no campo.

\section{Considerações finais}

Considerar a população em situação de rua como campo exigiu o exercício empírico e analítico, em um movimento reflexivo. Podemos defini-la de duas formas distintas: relacionar sua condição como a sucessão de eventos que precederam sua chegada às ruas (processo de desfiliação) e em referência a condição em que se encontram já como pessoa em situação de rua. Essas abordagens equivalem aos conceitos formulados por Bourdieu de miséria de condição, dado por condições objetivas e na oposição com outras classes, o que torna este conjunto populacional aparentemente homogêneo entre si e distante dos demais da sociedade, e miséria de posição, dados por grupos de status e sistemas de valores que, embora invertidos na ordem vigente, demonstra posições classificáveis dentro do campo.

A evolução das nomenclaturas representa formas de apropriação e visibilidade deste segmento para as políticas públicas. A análise dos dados permite observar a diferença entre os acolhidos vinculados, os acolhidos pernoite, e aqueles que, vivendo nas ruas, estão relativamente adaptados ou absolutamente adaptados. Na perspectiva geográfica a posição de rua pode ser entendida nas territorialidades de acesso aos recursos. Também a relação temporal permite diferenciação de habitus e capitais fundamentais à sobrevivência nas ruas, tais como linguagem, fontes de alimentação, formas de auferir renda e pontos de elevada infraestrutura urbana.

O campo constitui-se em espaço delimitado por fronteiras simbólicas. Para aprofundar o entendimento dessas fronteiras, buscou-se compreender a relação de coerção e coação das instituições. As trajetórias, as idas e vindas, contam a série de posições consecutivamente ocupadas pelo sujeito, ainda

\footnotetext{
${ }^{8}$ Segundo Censo de 2015: 63\% dos acolhidos e 64\% dos que pernoitam nas ruas sofreram violência física de outra pessoa em situação de rua, além das violências sofridas pelos agentes policiais - cerca de $35 \%$ - e pelos transeuntes $-24 \%$.
} 
que de maneira inconsciente, em estados sucessivos do campo. O processo de aquisição de novos habitus resulta da negociação do status, das regras impostas pela rede de acolhimento e da própria situação de rua. Resultando na identificação daqueles que incorporando os discursos institucionalizados estão saindo do campo. Também identificamos aqueles que mantêm uma relação pontual de negociação desse status, seja por estarem entrando no campo ainda com certa inadequação às regras, ou pela adaptação relativa ou absoluta ao campo submetendo-se às regras. A hierarquia de posições inclui reconhecer que indivíduos isolados, pernoitando nas ruas, resistentes à institucionalização, estão no topo e que os acolhidos, vagas fixa ou lideranças se afastam do campo.

Considerar a temporalidade dessa condição em menor ou maior grau é reconhecê-la como parte de um contínuo da precariedade, saber que existem idas e vindas sem necessariamente representar superação da condição. Por isso, não se trata de um fenômeno restrito a uma cidade ou país, a um indivíduo ou grupo. É justamente neste tocante que vislumbramos a possibilidade de compreensão da hierarquia de posições e condições, representando aquisição de novos habitus e de novas regras, envolvendo processos de inculcamento de discursos, envolve sofrimento, fragilidades, instabilidades e resistências dentro das estruturas sociais de classe e de poder.

\section{Referências}

BRASIL. Lei de 16 de dezembro de 1830. I Código Criminal do Império do Brazil. Brasília, 1830 <planalto.gov.br/ccivil_03/leis/lim/LIM-16-12-1830.htm>.

BRASIL. Decreto n. 7.053 de 23 de dezembro de 2009. Institui a Política Nacional para a População em Situação de Rua e seu Comitê Intersetorial de Acompanhamento e Monitoramento, e dá outras providências. Brasília, 2009 <planalto.gov.br/ ccivil_03/_ato2007-2010/2009/decreto/d7053.htm>.

BOURDIEU, Pierre. Razões práticas: sobre a teoria da ação. Campinas: Papirus, 2011. BOURDIEU, Pierre. Espaço social e poder simbólico. In: Pierre Bourdieu. Coisas ditas. São Paulo: Brasiliense, 1990. p. 149-168.

COPS/SMADS. Sistema de Atendimento aos Usuários (Sisa), 30 de junho de 2015 $<$ sisa.prefeitura.sp.gov.br/sisa1/PaginasPublicas/login.aspx>.

COPS/SMADS. Operação baixas temperaturas - série histórica das abordagens à população em situação de rua (2009 a 2017). São Paulo: PMSP/Smads, 2018 <prefeitura.sp.gov.br/cidade/secretarias/upload/assistencia_social/arquivos/OBT_ Serie_Historica_2009-2017_(OUTROS).pptx>.

COPS/SMADS/FIPE. Pesquisa censitária da população em situação de rua, caracterização socioeconômica da população adulta em situação de rua e relatório temático de identificação das necessidades desta população na cidade de São Paulo: sumário executivo. São Paulo, 2015 < prefeitura.sp.gov.br/cidade/secretarias/upload/ assistencia_social/censo/SUMARIO\%20EXECUTIVO.pdf >. 
DE PERETTI, Gaël. Précaire: une catégorie instable et fragile. Empan, n. 60, p. 14-23, 2005.

DUARTE, Maria Tereza. Projeto Casa Primeiro: experiência de housing-first em Portugal. In: $1^{o}$ Seminário de Políticas para a População em Situação de Rua. São Paulo: BID/Prefeitura de São Paulo/Unifesp, agosto de 2018. Comunicação oral.

HARVEY, David. Espaços de esperança. 5. ed. São Paulo: Edições Loyola, 2012.

KOHARA, Luiz. Desafios para efetivação do direito à moradia para população em situação de rua: estudo de experiências de atendimento público nas cidades de São Paulo, Belo Horizonte, Fortaleza e Salvador. In: 1 o Seminário de Políticas para a População em Situação de Rua. São Paulo: BID/Prefeitura de São Paulo/Unifesp, agosto de 2018.

NEVES, Delma Pessanha. Categorizações deformantes: patrimônio de gestão dos pobres (mendigos, vagabundos, população em situação de rua). Antropolítica, n. 29, p. 9-35, 2010a <10.22409/antropolitica2010.0i29.a36>.

NEVES, Delma Pessanha. Habitantes de rua e vicissitudes do trabalho livre. Antropolitica, n. 29, p. 99-130, 2010b <10.22409/antropolitica2010.0i29.a40>.

PAUGAM, Serge. Desqualificação social: ensaio sobre a nova pobreza. São Paulo: Educ, 2003.

ROSA, Cleisa Moreno Maffei. Vidas de rua. São Paulo: Editora Hucitec/Associação Rede Rua, 2005.

RUFFIN, Amber. Amber invites white people to join the fun. 2016 <youtu.be/ veO56HqH8TA>.

SMADS/FIPE. Levantamento censitário e a caracterização sócio-econômica da população moradora de rua na cidade de São Paulo. São Paulo, $2000<$ prefeitura. sp.gov.br/cidade/secretarias/upload/assistencia_social/arquivos/Cops/Pesquisa/1. pdf>.

SMADS/FIPE. Censo da população de moradores em situação de rua e caracterização socioeconômica da população adulta na cidade de São Paulo. São Paulo, 2009 <prefeitura.sp.gov.br/cidade/secretarias/upload/assistencia_social/arquivos/Cops/ Pesquisa/6.pdf $>$.

STOFFELS, Marie-Ghislaine. Os mendigos na cidade de São Paulo: ensaio de interpretação sociológica. Rio de Janeiro: Paz e Terra, 1997.

VIEIRA, Maria Antonieta da Costa; BEZERRA, Eneida Maria Ramos; ROSA, Cleiza Maria Maffei (orgs.). População de rua: quem é, com quem vive, como é vista. 2. ed. São Paulo: Hucitec, 1994.

WACQUANT, Loïc J. D. A zona. In: Pierre Bourdieu (org.) A miséria do mundo. Petrópolis: Vozes, 2003. p. 177-201.

WEBB, Olivia. Voiceless: the construction of homelessness policies from 1980-2016. In: DCC, The Andrea Mitchell Center for the Study of Democracy. 2017 - DCC Undergraduate Research Conference. Abstracts and papers. Philadelphia: University of Pennsylvania, $2017<$ sas.upenn.edu/andrea-mitchell-center/sites/www.sas.upenn. edu.andrea-mitchell-center/files/uploads/Webb\%20Paper.pdf>. 
Recebido: 31 maio 2018

Aceito: 29 nov. 2018

Publicado: 01 mar. 2019

Autora correspondente:

Carolina Teixeira Nakagawa Lanfranchi

Alameda dos Araés, 679 - Planalto Paulista

04066-002 São Paulo, SP, Brasil

CAROLINA TEIXEIRA NAKAGAWA LANFRANCHI <cnakagawalanfranchi@gmail.com>

Bacharel em Ciências Sociais (PUC-SP), Mestre em Arquitetura e Urbanismo, área de concentração Habitat (FAU/USP-SP), Doutoranda no Programa de Estudos Pós-Graduados em Ciências Sociais (PUC-SP). Pesquisadora do Observatório das Metrópoles de São Paulo (São Paulo, SP, Brasil).

Orcid: https://orcid.org/0000-0001-5925-9664

VIVIANE CANECCHIO FERREIRINHO < vferreirinho@gmail.com>

Bacharel em Ciências Sociais (FFLCH/USP-SP), Mestre e Doutora em Educação: História, Política e Sociedade (PUC-SP), pesquisadora chefe do Centro de Pesquisa e Memória Técnica do Observatório de Políticas Sociais. Coordenação do Observatório da Vigilância Socioassistencial da Secretaria Municipal de Assistência e Desenvolvimento Social de São Paulo.

Orcid: https://orcid.org/0000-0001-7724-8678 